\title{
Les campagnes gallo-romaines du Centre-Cotentin
} $n^{\circ} 3368$

\section{Aurore Di Liberto}

\section{(2) OpenEdition}

\section{Journals}

Édition électronique

URL : http://journals.openedition.org/adlfi/16712

ISSN : 2114-0502

Éditeur

Ministère de la culture

Référence électronique

Aurore Di Liberto, «Les campagnes gallo-romaines du Centre-Cotentin », ADLFI. Archéologie de la France - Informations [En ligne], Basse-Normandie, mis en ligne le 26 février 2016, consulté le 20 avril 2019. URL : http://journals.openedition.org/adlfi/16712

Ce document a été généré automatiquement le 20 avril 2019

(c) Ministère de la Culture et de la Communication, CNRS 


\section{Les campagnes gallo-romaines du Centre-Cotentin}

$n^{\circ} 3368$

Aurore Di Liberto

Lien Atlas (MCC) :

1 Le Centre-Cotentin, entre Coutances et Valognes du nord au sud et entre Portbail et Carentan de l'est à l'ouest, présente la particularité de ne faire l'objet d'aucune fouille se rapportant à l'époque antique et ce, depuis plus de 150 ans.

2 En effet, la Carte archéologique de la Manche recense les découvertes des érudits du XIX siècle et révèle que cette région recèle des vestiges antiques dans un bon nombre de communes. Une prospection, réalisée dans le cadre d'un master 2 , couvrant une soixantaine de communes, a été menée afin de vérifier les dires de ces antiquaires. Dans certaines parcelles, la prospection a été rendue difficile voire impossible par les mauvaises conditions de visibilité (aménagement urbain, tapis végétal dense...).

3 Cependant, de belles découvertes sont à mentionner et prouvent ainsi la nécessité de s'intéresser davantage à cette région trop longtemps négligée. La commune de Saint-Jores par exemple, qui a déjà fait l'objet d'une campagne de prospection (master 1-2012), a révélé cette année un alignement de tuiles à rebords conduisant à une zone de rubéfaction dont des probables rejets de verres ont été ramassés. La commune de Cretteville, à environ $7 \mathrm{~km}$ de Saint-Jores, a abouti à de nombreuses découvertes dont une plausible villa, déjà évoquée par Charles Duhérissier de Gerville au XIX ${ }^{\mathrm{e}}$ s., où le ramassage en surface confirme la présence de tuiles à rebord, d'huîtres, de moellons etc. mais très peu de céramiques. À Saint-Côme-du-mont et à Carentan, deux tessons de sigillés ont été repérés. À Fresville, des enclos supposés protohistoriques ont été décelés par vues aériennes. 
4 La prospection qui a été menée a su démontrer la présence de vestiges antiques, confirmant ainsi les recherches menées il y a un siècle et demi. Ces résultats nécessitent maintenant une recherche plus approfondie, envisagée dans les années qui vont suivre.

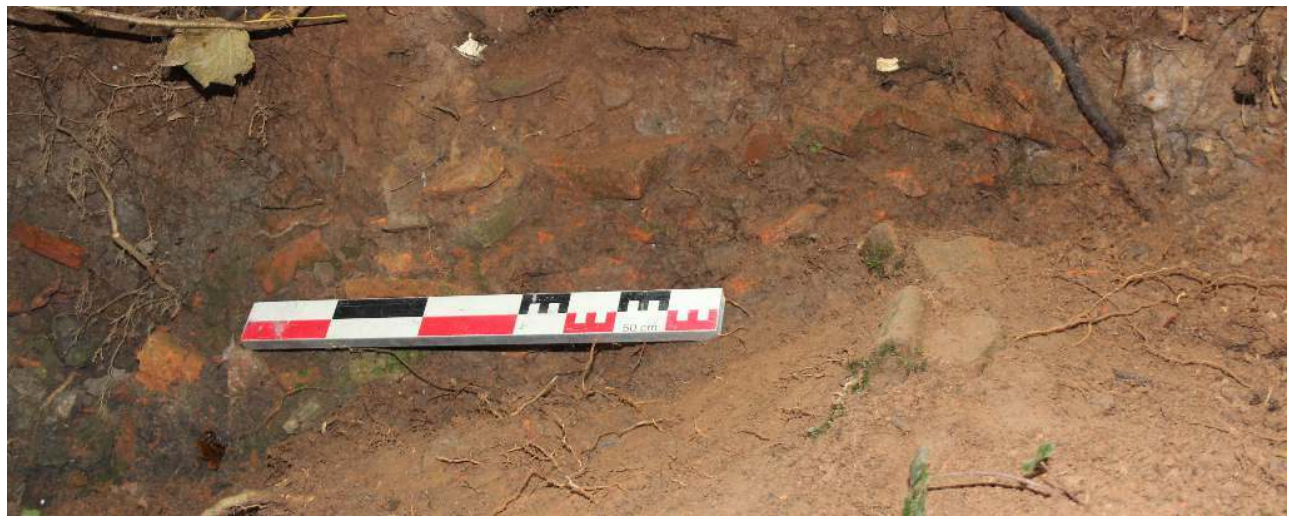

Fig. 01

Saint-Jores, rivière de la Senelle. Alignement de tuiles à rebord

Cliché A. Di Liberto

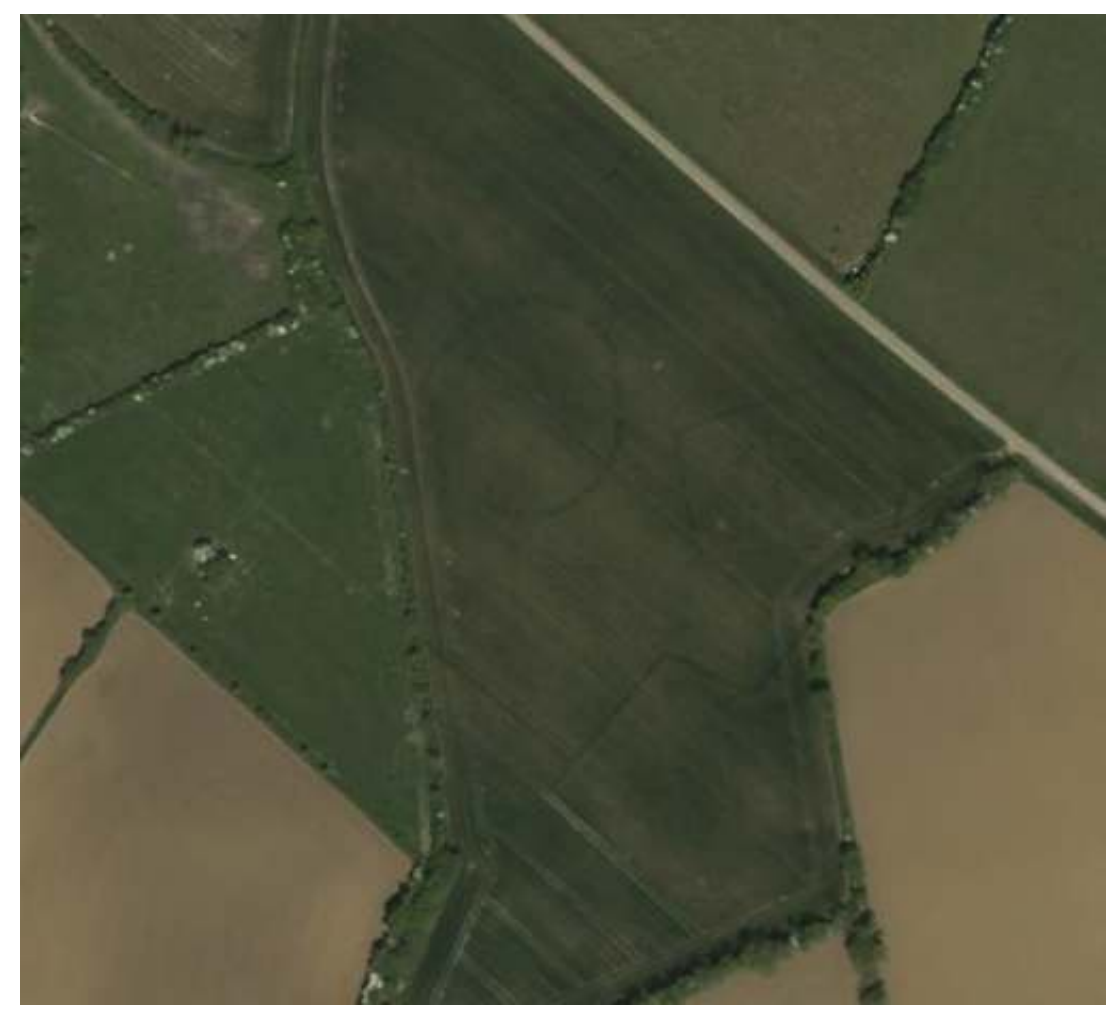

Fig 02

Fresville, le Houelbec. Traces de trois enclos repérés sur clichés de l'IGN. 
INDEX

Index chronologique : Antiquité

Index géographique : Basse-Normandie, Manche (50)

Mots-clés : céramique, tuile

operation Prospection diachronique (PRD)

\section{AUTEURS}

AURORE DI LIBERTO

BEN 